Спичак И.В. ${ }^{1}$,

Дереглазова Ю.С. ${ }^{2}$, Петровская T.Ю. ${ }^{3}$

\author{
АНАЛИЗ АССОРТИМЕНТА УНК «АПТЕКИ БеЛГУ» \\ ПО ЛЕКАРСТВЕННЫМ СРЕДСТВАМ ДЛЯ ЛЕЧЕНИЯ \\ ЮВЕНИЛЬНОГО АРТРИТА
}

1) доктор фармацевтических наук, профессор, заведующая кафедрой управления и экономики фармации, НИУ «БелГУ». 308015, г. Белгород, ул. Победы, 85, Россия. E-mail: Spichak@ bsu.edu.ru

2) ассистент кафедры управления и экономики фармации НИУ «БелГУ»

308015, г. Белгород, ул. Победы, 85, Россия. E-mail: dereglazova@ bsu.edu.ru

3) кандидат медицинский наук, врач - ревматолог, детский кардиолог, МБУЗ «Городская детская больница», 308014, г. Белгород, ул. Садовая, 1А, Россия, E-mail: rheumo@list.ru

\begin{abstract}
Аннотация. В статье представлены результаты анализа российского и регионального фармацевтического рынка и ассортимента лекарственных средств УНК «Аптеки БелГУ» для лечения ювенильного артрита; разработаны рекомендации для оптимизации ассортиментной политики УНК «Аптеки БелГУ» по препаратам для лечения ювенильного артрита.

Ключевые слова: фармацевтическая помощь; лекарственные средства; дети; артриты; аптеки
\end{abstract}

Spichak I.V. ${ }^{1}$,

Dereglazova Yu.S. ${ }^{2}$,

Petrovskaya T.Yu. ${ }^{3}$

\section{ANALYSIS OF THE BSU PHARMACY'S ASSORTMENT OF MEDICINES FOR THE TREATMENT OF JUVENILE ARTHRITIS}

1) Doctor of Pharmacy, Professor, Head of Department of Management and Economics of Pharmacy

Belgorod State National Research University, 85 Pobedy St., Belgorod, 308015, Russia. E-mail: Spichak@ bsu.edu.ru

2) Assistant Lecturer. Department of Management and Economics of Pharmacy

Belgorod State National Research University, 85 Pobedy St., Belgorod, 308015, Russia. E-mail: dereglazova @ bsu.edu.ru

3) $\mathrm{PhD}$ in Medicine, Rheumatologist, Pediatric Cardiologist, City Children's Hospital,

1A Sadovaya St., Belgorod, 308014, Russia. E-mail: rheumo@list.ru

\begin{abstract}
The article presents the results of the analysis of the Russian and regional pharmaceutical market and the BSU Pharmacy's assortment of medicines used in the treatment of juvenile arthritis; the authors offer their recommendations for optimizing the BSU Pharmacy's assortment policy on drugs for the treatment of juvenile arthritis.
\end{abstract}

Key words: pharmaceutical care; medicines; children; arthritis; pharmacies

\section{Введение.}

На сегодняшний день хронические воспалительные заболевания суставов у детей актуальная проблема современной педиатрической ревматологии. В России проживает около 600 тыс. детей с ограниченными возможностями. Одним из тяжелейших заболеваний, которому подвержены дети в возрасте от 3 месяцев до 17 лет, является юношеский (ювенильный) артрит (ЮA) $[1,2,3]$.

ЮА обладает тенденцией к хроническому прогрессирующему течению, оказывающему значительное влияние на качество жизни больного ребенка, а главное, является причиной развития детской инвалидности, которая наступает в течение первых 10 лет болезни у 50 \% детей с поражениями суставов.

В настоящее время фармацевтический рынок лекарственных средств (ЛС) представлен значительным спектром препаратов, применяемых для лечения ЮА. Актуальным является изучение региональных тенденций его формирования путем проведения маркетинговых исследований.

Целью работы является - анализ ассортимента УНК «Аптеки БелГУ» по лекарственным средствам для лечения ювенильного артрита

Объекты исследования: официальные источники информации о зарегистрированных в РФ ЛС (Государственный реестр лекарственных средств); программное обеспечение 
«АналитФармация» г. Белгород; отчет по продажам ЛС в УНК «Аптеки БелГУ» за 2015 г.

Методы и методы исследования: структурный, графический, методы маркетингового и математического анализов, экономико-математические

группировки, ранжирования).

(сравнения,

Результаты исследования и их обсуждение.

Для реализации поставленной цели сформирована концепция исследования, включающая 4 этапов: разработка макроконтура российского рынка препаратов, предназначенных для лечения ЮА; формирование мезоконтура регионального рынка ЛС для лечения ЮА; изучение ассортимента УНК «Аптеки БелГУ» для лечения ЮА и формирование микроконтура; разработка рекомендаций по оптимизации ассортиментной политики УНК «Аптеки БелГУ» в области лекарственных средств для лечения ювенильного артрита.

В основу маркетингового анализа рынка положен методический подход который включает следующие этапы: сбор информационного массива данных; структурный анализ ассортимента ЛС; детальный внутригрупповой анализ препаратов; анализ лекарственных форм (ЛФ) по составу; сегментационный анализ по производственному признаку; сегментирование ассортимента по виду ЛФ; формирование макро - / мезо -/ микроконтуров ЛС.

Так, в ходе анализа официальных источников информации установлено, что информационный массив ЛС для лечения ЮА включает 620 препаратов, 25 торговых наименований (ТН) и 14 международных непатентованных наименований (МНH) ЛС из 5 фармакотерапевтических групп (ФТГ).

Сформирован макроконтур фармацевтического рынка ЛС, применяемых для лечения ЮА, который включает 620 препаратов из 5 ФТГ. Установлено, что он, в основном, формируется противовоспалительными и противоревматическими препаратами - 89,0\%, производные уксусной кислоты- 92,8 \%, монокомпонентного состава - 97,0\%, отечественного производства $60,0 \%$, лидирует компания - производитель Озон OOO- 25,0\%. В структуре ассортимента преобладают твердые ЛФ - 50,7\%, в частности таблетки, покрытые кишечнорастворимой оболочкой - 65,0\%. Средний индекс обновления ассортимента составляет $-45,0 \%$.
На следующем этапе составлен мезоконтур регионального рынка ЛС, применяемых для лечения ЮА, который, в основном, формируется противовоспалительными и противоревматическими препаратами - 89,0\%, по химическому составу препараты производные уксусной кислоты - 92\%, монокомпонентного состава - 97,0\%, отечественного производства - 58,2 \%, лидирует компания - производитель Озон ООО - 28,7\%. В структуре ассортимента преобладают твердые ЛФ - 50,0\%, в частности таблетки, покрытые кишечнорастворимой оболочкой $-55,6 \%$. Средний индекс обновления ассортимента составляет $-45,0 \%$.

Установлено, что ассортиментный контур регионального рынка для лечения ЮА входит в границы российского и аналогичен ему по основным критериям. Определены основные направления развития регионального рынка. Так, на наш взгляд, к ним следует отнести: увеличение ассортиментного ряда ЛС для детей; расширение границ предложений препаратов для лечения ЮА, в частности, за счет увеличения доли комбинированных и пролонгированных средств, в том числе, препаратов отечественного производства и др.

На третьем этапе проанализирован ассортимент ЛС для лечения ювенильного артрита на базе УНК «Аптеки БелГУ». Так, установлено, что структуру аптечного ассортимента по ФТГ согласно АТХклассификации формируют 5 групп ЛС для лечения ЮА, среди которых первую ранговую позицию занимают средства, влияющие на костно-мышечную систему (M) - 82,0\%; остальную долю составляют гормоны для системного применения (исключая половые гормоны) (H) - 14,4\%, противоопухолевые и иммуномодулирующие препараты (L) - 2,2\%; средства, влияющие на пищеварительный тракт и обмен веществ (А) - 1,2\%; а также противопаразитарные препараты, инсектициды и репелленты (P) - 0,2\%. В ходе детального внутригруппового анализа выявлено, что среди средств, влияющих на костно-мышечную систему, противовоспалительные и противоревматические препараты занимают $89,3 \%$; группа средств для местного лечения при болевом синдроме при заболеваниях костно-мышечной системы - 10,7\%. Группа противовоспалительных и противо- 
ревматических препаратов, в основном, представлена производными уксусной кислоты - 92,4\%, производными пропионовой кислоты $-3,0, \%$, а также оксикамами $-4,6 \%$. В общей структуре ассортимента доминирующая часть принадлежит монокомпонентным препаратам - 96,5\%, комбинированные составляют - 3,5\%. В ходе сегментационного анализа ЛС по производственному признаку выявлено преобладание доли ЛС российского производства - 62\%, остальные $38 \%$ зарубежные препараты.

Анализ предложений ассортимента ЛС аптеки по зарубежным странам-производителям показал, что ЛП для лечения ЮА предлагают 13 стран. Среди них первое место принадлежит Индии - 27,6\%, за ней следуют Словения - 19,9\% Германия - 18,6\%; на следующей позиция находятся Сербия - 6,4\% и Нидерланды $-6,4 \%$. Швейцария - 5,1 \%, соответственно. На долю прочих стран приходится $16 \%$.

Анализ предложений ассортимента ЛС УНК «Аптеки БелГУ» порубежным производителям показал, что ЛП для лечения ЮА предлагают 18 иностранных фармацевтических фирм. Среди них первый рейтинг принадлежит компании M.J.Biopharm $15,4 \%$. Второе место занимает Shreya Life Scienses-12,2\%, третье KRKA -11,5\%. 4 место Boehringer Ingelheim International - 10,8\%; далее следуют компании Sandoz d. d. -8,3; Hemofarm 6,4\%; Natur Produkt Europe B.V. - 6,4\%; Medac $5,8 \%$; Sopharma AD - 4,5\%; Gedeon Richter$3,8 \%$; на долю прочих приходится $-14,9 \%$.

Анализ предложений ассортимента ЛС аптечного ассортимента по отечественным производителям показал, что препараты для лечения ЮА предлагают 27 российских фармацевтических фирм. Среди них первое место принадлежит компании ООО Озон $36,2 \%$; второе место занимает Московский эндокринный завод -10,6\%, третье Сандоз $3 \mathrm{AO}-$ 6,7\%; далее следуют Биосинтез ОАО -6,3\%; Новосибхимфарм - 5,9\%, а также Уралбиофарм
ОАО - 5,5\% и Биохимик - 5,5\%; Сотекс Фарм Фирма - 3,9\%; Новартис Фарма ООО - 3,5\%; Синтез Акционерное Курганское общество медицинских препаратов и изделий $\mathrm{OAO}-2,8 \%$. На долю остальных отечественных фирм-производителей приходится 13,1\%.

Анализ ЛФ ассортимента аптеки ЛС для лечения ЮА показал, что доля твердых ЛФ для лечения ЮА составляет 56,0\%, жидких - 28,0\% и мягких - $16,0 \%$ в общей структуре ассортимента.

Среди твердых ЛФ доминируют таблетки, покрытые кишечнорастворимой оболочкой 55,6\%; далее следуют таблетки, - 21,9\%; таблетки пролонгированного действия, покрытые оболочкой $-8,1 \%$; таблетки, покрытые оболочкой - по 7,4\%. Таблетки покрытые плёночной оболочкой 2,2\%; капсулы и также таблетки пролонгированного действия составляют по 1,9\% соответственно; таблетки пролонгированного действия, покрытые оболочкой - $0,7 \%$ и капсулы с модифицированным высвобождением- $0,3 \%$ от общего количества твердых ЛФ для лечения ЮА.

На долю БАД приходится лишь 0,2\% всего ассортимента ЛС. Установлено, что в ассортименте УНК «Аптеки БелГУ» присутствует 248 новых препаратов, а средний индекс обновления ассортимента составляет $33,9 \%$, что свидетельствует о наличии меньшего количества новых ЛС в аптечном ассортименте по сравнению с ассортиментом российского и регионального рынков для лечения ювенильного артрита.

Составлен микроконтур ассортимента УНК «Аптеки БелГУ» для лечения ювенильного артрита, который входит в границы российского и регионального контуров, аналогичен им по основным критериям, однако, уступает по диапазону предложенных препаратов, а также по степени обновлённости ассортимента (рисунок 1). 


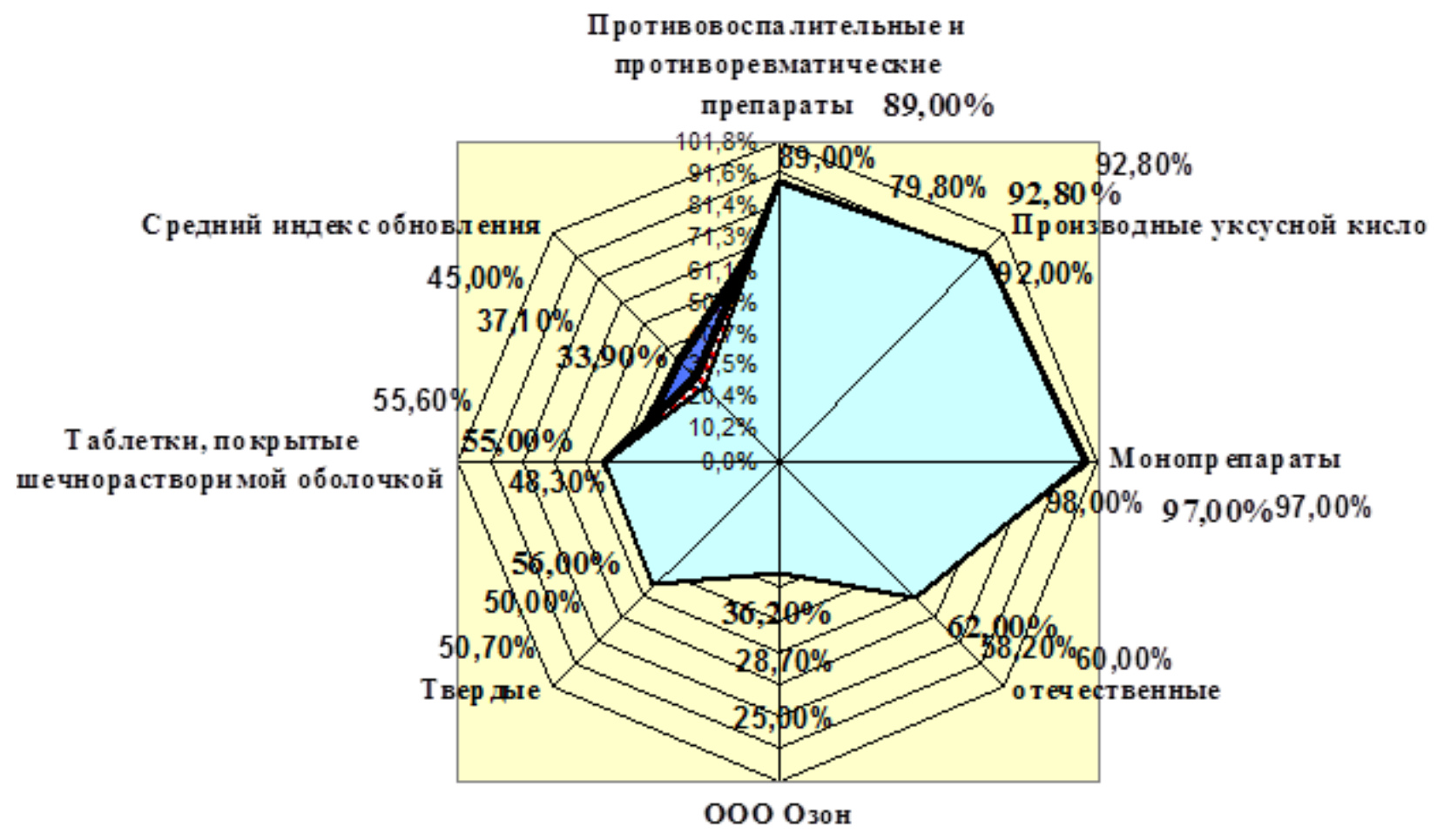

\section{ШРоссийский рынок Белгородский рынок ВУнк "Аптеки БелГу"}

Puc. 1. Ассортиментные макро- и мезоконтуры российского и Белгородского рынков ЛС для лечения ювенильного артрита, \%

Fig. 1. Assortment macro- and mesocontours of Russian and Belgorod markets for medicines used in the treatment of juvenile arthritis, \%

\section{Заключение.}

На заключительном этапе определены основные стратегические направления оптимизации ассортиментной политики УНК «Аптеки БелГУ» по препаратам для лечения ювенильного артрита, так, в частности:

- Необходимость обновления ассортимента в области ЛС для лечения ювенильного артрита в соответствии с региональными показателями и российскими показателями;

- Изучение спроса на лекарственные препараты для лечения ювенильного артрита, в особенности на препараты группы иммунодепрессантов для последующего включения в ассортимент;

- Определение предпочтений потребителей в выборе лекарственной формы для лечения детей с ювенильным артритом;

- Увеличение доли комбинированных и пролонгированных средств и др.

\section{Литература}

1. Баранов А.А., Алексеева Е.И., Бзарова Т.М. Ювенильный ревматоидный артрит // Клинические рекомендации. Педиатрия (Ювенильный ревматоидный артрит). Москва, 2005. С. 32.

2. Спичак И.В., Панкратова О.Г., Автина Н.В. Оптимизация лекарственного обеспечения детей с тонзиллитами в амбулаторно - поликлинических учреждениях // Научные ведомости Белгородского государственного университета. Сер. Медицина. Фармация. 2010. №22 (93), вып. 12. С.154-159.

3. Ravelli A, Martini A. Juvenile idiopathic arthritis. Lancet. 2007.№369 (9563). Pp.767-778.

\section{References}

1. Baranov A.A., Alekseeva E.I., Bzarova T.M. Juvenile Rheumatoid Arthritis // Clinical Guidelines. Pediatrics (Juvenile rheumatoid arthritis). Moscow, 2005. P. 32.

2. Spichak I.V. Pankratova, O.G., Altina N.V. Optimization of Provision of Medicines to Children with Tonsillitis in Outpatient Facilities // Belgorod State University Scientific Bulletin. Medicine Pharmacy. 2010. №. 22 (93), V. 12. Pp. 154-159.

3. Ravelli A, Martini A. Juvenile idiopathic arthritis. Lancet. 2007. №369 (9563). Pp.767-778. 